\title{
Informes do Programa de Pós-graduação do Instituto de Estudos Brasileiros
}

Iniciado em 2009, o programa IEB, Culturas e Identidades Brasileiras, sediado no Instituto de Estudos Brasileiros, constitui um programa interdisciplinar de mestrado stricto sensu que objetiva fomentar estudos e reflexões sobre a cultura e a sociedade brasileira. A interdisciplinaridade é constitutiva não só da proposta do Curso, como também do próprio Instituto de Estudos Brasileiros, uma vez que a instituição criada em 1962 por Sérgio Buarque de Holanda nasceu com este princípio integrador das áreas de conhecimentos que compõem nas Artes e Humanidades. O corpo docente do programa é composto por professores provenientes de diversas áreas que compõem as artes, literatura e ciências humanas, fomentando assim diálogos entre perspectivas distintas, capazes de transcender os limites disciplinares. O programa estruturase em uma única área de concentração (Estudos Brasileiros) e possui duas Linhas de Pesquisa: 1) "Sociedade e Cultura na América Portuguesa e no Brasil" e 2) "Brasil: a realidade da criação, a criação da realidade", as quais agrupam um recorte cronológico amplo, contemplando estudos sobre Brasil do século XVI ao XXI.

A linha 1, intitulada "Sociedade e Cultura na América Portuguesa e no Brasil”, compreende a(s) cultura(s) em sua expressão mais ampla, na complexidade das relações entre e dentro de um determinado grupo social, na urdidura da sociedade, abrangendo assim trabalhos que se configuram como interdisciplinares ou multidisciplinares. Assim, parte-se do diálogo entre as múltiplas áreas do saber, enquanto lócus privilegiado da compreensão das tensões sociais, para a construção de interpretações da cultura na América portuguesa e no Brasil. Trata-se de estudar as possibilidades de diálogo entre enfoques teóricos, metodológicos e técnicas de pesquisa em múltiplas áreas do saber, no que se refere à interpretação do Brasil, explorando questões em torno das mediações entre análise interna e externa de documentos de natureza histórica, geográfica, literária, artística ou outros, e da discussão de conceitos como experiência, ideologia, representação e identidade.

A linha 2 denomina-se "Brasil: a realidade da criação, a criação da realidade". Ela compreende estudos de teorias da criação artística, ensaística e científica calcados em documentos particulares, tais como discursos visuais, discursos linguísticos, imagens, sons (independentemente da mídia em que se encontram registrados), os quais são conformados a partir do universo social de seus produtores. Nesta 
perspectiva, agentes e objetos são vistos concomitantemente como produtores e produtos dos meios (artísticos, literários, musicais, científicos) aos quais se vinculam. As pesquisas desenvolvidas na linha 2 privilegiam, portanto, os estudos críticos sobre o processo criativo, o qual é considerado um construtor de realidades - a realidade dos documentos (literários, artísticos, musicais, publicitários, midiáticos,etc.) - as quais devem ser analisadas/interpretadas mediante pesquisas multidisciplinares que dêem conta de suas complexidades intrínsecas.

Até o momento já foram defendidas 12 dissertações no programa. Nestas evidencia-se o primado da qualidade acadêmica, por meio de pesquisas originais, pautadas pelo princípio da interdisciplinaridade.

Ana Paula Cavalcanti Simioni, Docente e Presidente da Comissão de Pós-Graduação do IEB-USP

Autora: Ana Luisa Dubra Lessa

Orientador: Prof. Dr. Marcos Antonio de Moraes

Data da defesa: $26 / 10 / 2012$

Título da Dissertação: Edição da correspondência Mário de Andrade \& Ascenso Ferreira e Stella Griz Ferreira - 1926-1944

Resumo: Esta dissertação apresenta a edição fidedigna e anotada da correspondência do polígrafo modernista Mário de Andrade (1893-1945), com o poeta pernambucano Ascenso Ferreira (18951965) e sua esposa, Stella Griz Ferreira (1898-1974). A transcrição integral de 138 cartas, pertencente ao Arquivo Mário de Andrade, no Instituto de Estudos Brasileiros da Universidade de São Paulo, a recomposição cronológica dos diálogos, considerando a parcela de cartas de Mário ao casal, já publicadas em livros, e o procedimento de anotação das mensagens epistolares buscam ampliar o conhecimento das redes de sociabilidade no modernismo brasileiro, oferecendo elementos biográficos e testemunhais para o estudo da obra dos interlocutores e de seus processos de criação. A análise da correspondência, em perspectiva interdisciplinar, apreende os principais pontos da discussão acerca da criação poética e das manifestações folclóricas do nordeste brasileiro. 
Autor: André Gilberto da Silva Fróes

Orientador: Prof. Dr. Alexandre de Freitas Barbosa

Data da defesa: $18 / 03 / 2014$

Título da Dissertação: Do urupê de pau podre à maquinização Monteiro Lobato e a formação nacional (c. 1914 - 1941)

Resumo: O presente trabalho aborda a trajetória e produção intelectual de Monteiro Lobato a partir de sua vinculação à questão nacional, expressa, na perspectiva do escritor, como malformação. Neste sentido, a pesquisa procurou investigar as distintas formas de abordagem do problema em dois momentos do itinerário do autor, conectados a diferentes períodos da experiência histórica nacional: o projeto literário lobatiano inicial (c. 1914-1925), vinculado, em um contexto de questionamento sobre a viabilidade da nação brasileira, ao nacionalismo paulista em construção e ao esforço de elaboração da particularidade nacional; e a tentativa de implementação, durante a década de 1930, de uma proposta específica de modernização econômica, então erigida como a resposta do autor para o desafio da formação nacional. Esta é uma pesquisa de caráter multidisciplinar que transita pelas áreas da história cultural e da história econômica, manejando conceitos da sociologia e procedimentos da crítica literária.

Autora: Camila Russo de Almeida Spagnoli

Orientadora: Prof. ${ }^{a}$ Dr. ${ }^{\text {a }}$ Therezinha Apparecida Porto Ancona Lopez

Data da Defesa: $21 / 03 / 2014$

Título da Dissertação: Monteiro Lobato, o leitor

Resumo: Este trabalho se propõe a traçar um panorama das possíveis leituras realizadas por Monteiro Lobato, mediante o registro de referências a elas existentes nas cartas do escritor, e a pesquisa de obras que fizeram parte de suas estantes. A primeira parte da dissertação visa ao levantamento das leituras - autores e obras - citadas nas cartas remetidas por Lobato a Godofredo Rangel entre 1903 e 1948. As cartas compõem A barca de Gleyre: quarenta anos de correspondência literária entre Monteiro Lobato e Godofredo Rangel (Companhia Editora Nacional), coletânea editada pelo primeiro em 1944. A segunda parte dedica-se 
a estudar as relações do escritor com os títulos que restaram no Fundo Monteiro Lobato, depositado no CEDAE/ UNICAMP, e no acervo da Biblioteca Infantil Monteiro Lobato.

Autor: Conrado Augusto Barbosa Fogagnoli

Orientadora: Prof. ${ }^{a}$ Dr. ${ }^{a}$ Mayra Laudanna

Data da Defesa: 19/12/2012

Título da Dissertação: Entre texto e imagem: um estudo sobre as ilustrações de Sagarana

Resumo: Esta dissertação propõe hipóteses para se estabelecer relações entre alguns contos que compõem a primeira obra publicada por João Guimarães Rosa, Sagarana, e as duas versões de ilustrações que para ela foram feitas pelo gravador e ilustrador Poty Lazzarotto. Com o objetivo de expor como a crítica literária brasileira dos decênios de 1940 e 1950 entende a obra de João Guimarães Rosa, no primeiro capítulo analisa-se a recepção crítica das três primeiras obras publicadas pelo autor; o segundo capítulo trata da recepção crítica da obra de Poty Lazzarotto, evidenciando como esta crítica se ocupa apenas da construção de uma biografia estereotipada do artista, sem propor reflexões sobre sua obra; no terceiro e último capítulo, apresentam-se hipóteses que possibilitam relacionar alguns dos contos de Sagarana, de Guimarães Rosa, e as duas versões de ilustrações feitas por Poty Lazzarotto para esta obra.

Autor: Julio César de Oliveira Vellozo

Orientador: Prof. Dr. Paulo Teixeira Iumatti

Data da Defesa: $20 / 04 / 2012$

Título da Dissetação: Um Dom Quixote Gordo no Deserto do Esquecimento - Oliveira Lima e a construção de uma narrativa da nacionalidade

Resumo: O tema de nosso estudo é a obra do historiador e diplomata pernambucano Oliveira Lima, elaborada entre 1895 e 1928. Oliveira Lima construiu uma narrativa da nacionalidade que valorizou o papel da colonização portuguesa e afirmou como elementos distintivos das tradições nacionais as transições pactuadas, a ausência de rupturas e a tolerância diante das diferenças 
sociais e raciais. Esta interpretação foi elaborada justo em um momento no qual predominavam as visões anti-ibéricas e antimonárquicas, o que colocou Lima na contra-corrente da história e da História, transformando-o em um Quixote Gordo, na definição a um só tempo ácida e carinhosa de Gilberto Freyre. O autor considerava que três momentos fundamentais haviam forjado a nacionalidade: a vinda da corte portuguesa para o Brasil, a forma que tomou declaração de independência em relação a Portugal e o reinado de Dom Pedro II. Em meio a uma obra vastíssima, a tríade de escritos que informa esta narrativa da nacionalidade é, em nossa visão, composta por: Dom João VI no Brasil (1909), O Movimento da Independência (1921) e O Império Brasileiro (1928).

Autora: Lúcia Klück Stumpf

Orientadora: Prof. ${ }^{a}$ Dr. ${ }^{\text {a }}$ Ana Paula Cavalcanti Simioni

Data da Defesa: $12 / 03 / 2014$

Título da Dissertação: A terceira margem do rio: mercado e sujeitos na pintura de história de Antônio Parreiras

Resumo: Esta dissertação tem por tema a pintura de história de Antônio Parreiras (1860-1937) realizada durante a Primeira República (1889-1930). Busca compreender a atuação do pintor no embrionário mercado das artes do entresséculos XIX-XX, com ênfase nas relações estabelecidas com os poderes públicos. Pretende mostrar como Parreiras foi capaz de estimular a demanda por pinturas decorativas para os espaços públicos que estavam sendo construídos ou reformados a fim de atender as necessidades do novo regime. Discute como, nestas obras, se combinaram ditames do encomendante e vontade do artista, que, para além de cumprir os contratos, imprimiu nos quadros sua visão da história nacional. Propõe uma compreensão das telas históricas de Parreiras analisadas à luz dos debates artísticos, intelectuais e historiográficos da época. Nesse sentido, salientamos o capítulo final da dissertação, dedicado à análise da representação dos indígenas em sua obra. Através desta investigação pretende-se iluminar o papel desempenhado por Antônio Parreiras em um ambiente marcado por disputas simbólicas renhidas. 
Autora: Maria Aparecida Viana Schtine Pereira

Orientador: Prof. Dr. Fernando Augusto Magalhaes Paixão

Data da Defesa: $02 / 04 / 2013$

Título da Dissertação: O coruja, de Aluísio Azevedo: romance de formação sob o prisma do grotesco

Resumo: O termo Bildungsroman foi empregado pela primeira vez associado ao romance de Goethe, Os anos de aprendizado de Wilhelm Meister (1795-1796). Desde então, tornou-se uma linhagem literária de longa permanência na literatura. Na produção dos escritores brasileiros do século XIX, diferentemente do que ocorreu nos países europeus, o romance de formação não encontrou ressonância. Todavia, a obra O Coruja, de Aluísio Azevedo, alinha-se em tal categoria, e de forma muito particular. É o que pretende defender a presente dissertação, ao procurar entender a composição do texto e das personagens à luz do grotesco e da tradição deformante que essa perspectiva oferece. No percurso de análise, são utilizados conceitos de Mikhail Bakhtin, George Lukács e Marcus Mazzari, entre outros, com o intuito de verificar em que medida a história de André e Teobaldo pode ser lida como "um romance de formação às avessas", expressão última do meio social em que se desenvolve.

Autora: Magda Holan Yu Chang

Orientador: Prof. Dr. Alexandre de Freitas Barbosa

Data da Defesa: $15 / 04 / 2014$

Título da Dissertação: O padrão de inserção internacional da economia brasileira entre 1945 e 1980: Uma análise da interação entre política econômica e política externa

Resumo: Este trabalho visa a avaliar o papel da ação estatal, no âmbito da política econômica da política externa, para as mudanças no padrão de inserção internacional da economia brasileira entre 1945 e 1980, período em que o país consolidou-se como semiperiferia industrializada da "economia-mundo capitalista". Para além do arcabouço teórico de "sistemas mundo" utilizado para abarcar os determinantes sistêmicos que influíram sobre a inserção internacional da economia brasileira e sobre ambas as políticas econômica e externa, a dissertação recorre ainda às 
formulações das áreas da história econômica, economia política e relações internacionais para subsidiar a análise. Por fim, o trabalho realiza uma análise comparativa entre os instrumentos da política econômica e da política externa que atuaram sobre esse padrão de inserção, avaliando as formas de interação que se estabeleceram entre esses instrumentos e as suas implicações para a alteração da inserção internacional da economia brasileira.

Autora: Raquel Nunes Endálecio

Orientador: Prof. Dr. Marcos Antonio de Moraes

Data da Defesa: 08/04/2013

Título da Dissertação: A (re) Construção do mundo clássico na obra de Monteiro Lobato: fontes e procedimentos

Resumo: Esta dissertação se propôs a estudar a presença da Grécia clássica e mitológica na obra do escritor Monteiro Lobato (1892-1948), buscando verificar como as referências ao mundo helênico se impuseram em diversos momentos de sua produção literária (adulta e infantil), jornalística e memorialística. Com o objetivo de detectar fontes bibliográficas do autor, a pesquisa recuperou títulos de livros de sua biblioteca particular, atualmente dispersa, bem como menções a obras focalizando a Hélade em sua correspondência e em outros documentos. Colocando em pauta os processos de criação literária, o trabalho abordou as relações intertextuais entre obras de Lobato e títulos do historiador Will Durant (1885-1981) e do educador Virgil Hillyer (1875-1931), ambos estadunidenses. Explorou também o diálogo epistolar do criador de Urupês com o escritor maranhense Coelho Neto (1864-1934), reconhecido cultor da temática helênica. A dissertação apresenta "Seleta" de trechos da obra de Monteiro Lobato que focaliza aspectos históricos, linguísticos e culturais do mundo grego, a fim de contribuir para a ampliação do debate levantado.

Autor: Silvio Cesar Tamaso D'Onofrio

Orientador: Prof. Dr. Marcos Antonio de Moraes

Data da Defesa: 22/11/2012

Título da Dissertação: Fontes para uma biografia intelectual de Edgard Cavalheiro (1911-1958) 
Resumo: Esta dissertação apresenta o resultado da pesquisa que buscou realizar o levantamento exaustivo de documentação vinculada à trajetória intelectual do escritor paulista Edgard Cavalheiro (1911-1958), autor de Monteiro Lobato: vida e obra (1955) e criador do prêmio literário Jabuti. $\mathrm{O}$ escritor deixou uma ampla produção bibliográfica, composta de livros, traduções, separatas e de artigos dispersos em periódicos. Buscou-se também reunir a correspondência ativa e passiva do autor e elencar manuscritos conservados em seu arquivo, sob a guarda de herdeiros. Tendo Edgard Cavalheiro se notabilizado pela produção de biografias, a dissertação congrega uma seleta de seus artigos e textos em livro problematizando o assunto.

Autora: Valquiria Maroti Carozze

Orientadora: Prof. a Dr. ${ }^{a}$ Flávia Camargo Toni

Data da Defesa: 24/08/2012

Título da Dissertação: A menina boba e a discoteca

Resumo: Este trabalho se propõe analisar, interpretar e destacar o desempenho da musicóloga Oneyda Alvarenga, como diretora da Discoteca Pública Municipal de São Paulo (atual Discoteca Oneyda Alvarenga), trazendo a lume seu perfil de poeta, musicóloga e etnóloga, e de Mario de Andrade, como diretor do Departamento de Cultura da cidade e criador da seção que comportava o funcionamento da Discoteca Municipal; abordar seu papel como mentor de Oneyda Alvarenga; os esforços do intelectual modernista, crítico de arte e musicólogo no sentido de promover a busca de uma expressão genuinamente nacional da música brasileira. Propõe-se também a analisar a própria Discoteca Pública Municipal, seus objetivos, seu momento histórico e cultural, antes e durante o governo de Getúlio Vargas; o valor e o sentido da organização da documentação musical brasileira e latino-americana na época do Departamento de Cultura, sob diretoria de Mario de Andrade, segundo os propósitos do americanismo musical defendido por Curt Lange. Ainda sob o ponto de vista do americanismo musical, estabelecer relações entre os objetivos de difusão cultural mediante o trabalho de recuperação da música folclórica pela Missão de Pesquisas Folclóricas, a criação da Discoteca Pública Municipal e o contexto latino-americano, com sua atmosfera intelectual, que favorecia a criação de órgãos que pusessem 
à disposição documentos a serem pesquisados, refletindo sobre esse empreendimento no momento sócio-cultural brasileiro das décadas de 1930 e 1940, passando pelo viés da realidade brasileira, ao mesmo tempo gestada pela criação e universo social que propicia essa criação.

Autora: Vivian Chieregati Costa

Orientadora: Monica Duarte Dantas

Data da Defesa: $23 / 09 / 2013$

Título da Dissertação: Codificação e formação do Estadonacional brasileiro: o Código Criminal de 1830 e a positivação das leis no pós-Independência

Resumo: A presente dissertação realiza um exame histórico-jurídico do Código Criminal do Império do Brasil, aprovado em 16 de dezembro de 1830. Frequentemente interpretado como um documento liberal elaborado às pressas e artificialmente sobreposto à sociedade brasileira, o Código Criminal de 1830 foi muito pouco estudado pela historiografia nacional. Buscando desvendar a complexidade dos trabalhos e escolhas jurídicas e políticas envolvidas em sua composição, analisamos pormenorizadamente o trâmite parlamentar seguido por este documento (centrando-nos nos debates legislativos e comissões de trabalho dedicadas à sua elaboração), relacionando-o, ainda, ao movimento codificacionista ocidental em curso na virada do século XVIII ao XIX. Para além de examinar os projetos de código criminal apresentados ao legislativo brasileiro, entre 1826 e 1827, por José Clemente Pereira e Bernardo Pereira de Vasconcelos, realizamos uma análise comparativa cuidadosa entre o conteúdo destes projetos e o texto final do código aprovado, somando, ainda, a tal análise, uma comparação entre o Código de 1830 e os textos de dez códigos ou projetos de codificação penal existentes no mundo ocidental àquela altura. Partindo do corpus documental supracitado e da conjuntura política de aprovação deste diploma, a pesquisa desnudou as relações então travadas entre o direito penal e a política do Primeiro Reinado, articulando os dispositivos adotados pelo Código de 1830 às particularidades inerentes ao momento de sua aprovação e aos projetos de Estado, justiça e cidadania defendidos pelos parlamentares imperiais. Inserida e influenciada por um movimento internacional de larga escala e pautada por concepções jurídicas 
extremamente modernas, a positivação das leis penais no Império brasileiro atrelou-se à configuração do novo Estado-nacional e ao desejo de seus representantes de conformação de uma nova realidade.

DOI: http://dx.doi.org/10.11606/issn.2316-901X.v0i59p439-448 